\section{AN UNUSUAL RAVEN NEST SITE - ON A GRAIN ELEVATOR AT FOSSTON}

In March 1983 a pair of Common Ravens constructed a nest on the walkway between the main United Grain Growers elevator structure and the storage annex, 60 feet above the ground. The nest was about 2 feet in diameter and was built of sticks, paper and cattle hair.

Don Schultz, the elevator agent, calculates that the five eggs hatched early in April. When the young ravens began to walk around, they would follow Don into the annex to eat grain from the walkway floor - and he would chase them out, like chickens. There was a severe snowstorm on 12 May that year, and two of the young ravens died of exposure. The other three left the nest later.

This unusual event was reported, with a photograph, in the Wadena News of 14 April 1983. In 1984 the ravens attempted nesting again, on the same walkway, but the fire inspector considered the dry sticks and paper to be a fire hazard so the nest was destroyed.

Not only was this an unusual and noteworthy site, but the location is $20 \mathrm{mi}$. southwest of the nearest raven habitat around Greenwater Lake Provincial Park. - Kelly Kozij, Box 35, Hendon, Saskatchewan. SOE OXO
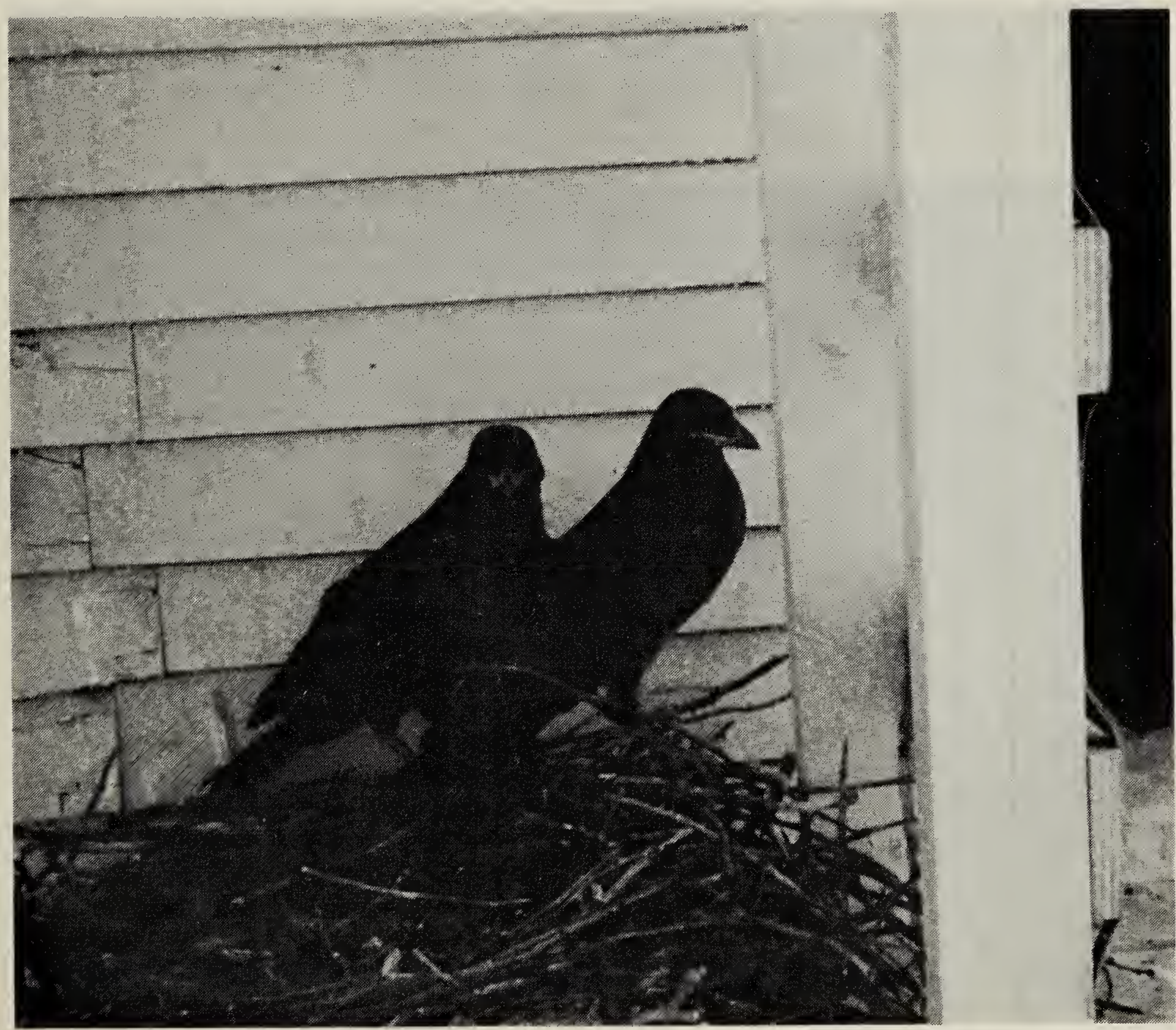